\title{
As 'línguas entre si' na universidade portuguesa: da fundação das Faculdades de Letras aos anos sessenta do séc. XX
}

Maria Hermínia Amado Laurel

\section{OpenEdition}

\section{Journals}

Edição electrónica

URL: https://journals.openedition.org/dhfles/887

DOI: 10.4000/dhfles.887

ISSN: 2221-4038

Editora

Société Internationale pour l'Histoire du Français Langue Étrangère ou Seconde

Edição impressa

Data de publição: 1 dezembro 2009

Paginação: 179-198

ISSN: 0992-7654

Refêrencia eletrónica

Maria Hermínia Amado Laurel, « As 'línguas entre si' na universidade portuguesa: da fundação das Faculdades de Letras aos anos sessenta do séc. XX », Documents pour l'histoire du français langue étrangère ou seconde [En ligne], 43 | 2009, mis en ligne le 16 janvier 2011, consulté le 27 mai 2021. URL : http://journals.openedition.org/dhfles/887 ; DOI : https://doi.org/10.4000/dhfles.887

Este documento foi criado de forma automática no dia 27 maio 2021.

(c) SIHFLES 


\title{
As 'línguas entre si' na universidade portuguesa: da fundação das Faculdades de Letras aos anos sessenta do séc. XX
}

\author{
Maria Hermínia Amado Laurel
}

1 Propor-me-ia abordar a emergência do ensino das línguas estrangeiras nas faculdades de letras em Portugal, no período que entremeia entre a sua fundação, em 1911, e os anos sessenta do séc. XX, período esse predominantemente marcado, do ponto de vista científico, por dominantes de índole filológica, e do ponto de vista político institucional, pelo triunfo das ideias republicanas no ensino e, a partir de 1926, pela ideologia do Estado Novo. Tentarei analisar esta situação referindo-me às motivações de ordem institucional, política e cultural que justificaram a criação das faculdades de letras e aos seus objectivos de formação, bem como à fundamentação científica da matriz filológica no ensino das línguas estrangeiras (mas também materna), os quais permanecem com pleno vigor até finais dos anos sessenta. Focalizarei a minha análise sobre o caso da Faculdade de Letras da Universidade de Coimbra, alma mater da universidade portuguesa desde os tempos medievais.

2 Para tal socorrer-me-ei essencialmente da leitura de várias orações de sapiência ${ }^{1}$ proferidas aquando da abertura de alguns anos lectivos naquela universidade no período supra mencionado. Obra de referência incontornável para o estudo da noção de filologia, as Lições de Filologia Portuguesa segundo as prelecções feitas aos cursos de 1911/1912 e de 1912/1913, por Carolina Michaëlis de Vasconcelos² (Seguidas de Lições práticas de Português arcaico), será de igual modo alvo de particular consideração ao longo deste artigo ${ }^{3}$.

3 A história das orações de sapiência « remonta porventura aos inícios desta Alma Mater ", segundo afirma José de O. Guimarães, na lição que profere a 16 de Outubro de 1926 (Guimarães [1926] $2002: 51^{4}$ ); ao tempo do Infante D. Henrique e da sua reforma universitária, para o historiador Damião Peres ${ }^{5}$, citado pelo seu representante Amorim 
Girão ${ }^{6}$, na interlocução que pronuncia no dia 25 de Outubro de 1952 (Girão [1948] 2002 : 141).

4 A oração de sapiência referente à lição inaugural do ano de 1912-1913 esteve a cargo de António de Vasconcellos ${ }^{7}$ (1860-1941), em substituição de Carolina Michaëlis, personalidade que o orador começa por reconhecer como « exímia filóloga, publicista distintíssima e professora abalizada [da] Universidade » (Vasconcellos [1912] 2002 : 19).

5 Traça o percurso dos estudos superiores em humanidades em Portugal até à criação das faculdades de letras que, para si, « não [constituem] uma novidade no organismo universitário » conimbricense (Vasconcellos [1912] 2002 : 20). Perspectivando historicamente o passado desta instituição, considera que, após o período brilhante da Faculdade das Artes medieval e renascentista, em que Coimbra era ponto de passagem obrigatória de grandes humanistas, como André de Gouveia, e esta faculdade projectava os conteúdos do seu ensino sobre as restantes, a sua decadência acentua-se após a entrega do ensino aí ministrado aos jesuítas, no séc. XVII e após Pombal. Refere Ribeiro de Vasconcellos que, entre $1791^{8}$ e 1911 , não houve ensino superior humanístico em Portugal (Vasconcellos [1912] 2002 : 24).

6 A criação de uma faculdade de letras era, compreende-se, uma pretensão antiga da Universidade de Coimbra. A resposta a esta lacuna acabaria por ser dada pelo decreto com força de lei de 19 de Abril de 1911, do Governo da República9 . Este diploma, que funda também as universidades de Lisboa e do Porto, atribuirá as duas faculdades de letras do país, uma à vetusta escola de Coimbra, e outra à recém criada na capital, respectivamente.

7 A leitura do citado decreto é surpreendente: a fundação das faculdades de letras é anunciada timidamente no contexto de um vasto programa de atribuição de bolsas de estudo $^{10}$. Tanto ou mais revelador se mostra por isso o discurso que Ribeiro de Vasconcellos profere nesse ano, na sua qualidade de primeiro director da Faculdade de Letras. Debruça-se com toda a oportunidade política sobre a importância da criação destas faculdades - que constata estarem representadas em todas as universidades de renome na Europa ${ }^{11}$-, justificando-a nestes termos :

Em toda a parte as Letras são consideradas a base de qualquer cultura superior. As Sciências não carecem de que lhes teça aqui o elogio, pois bem provada e evidente é a sua alta importância educativa, dando ao espírito a disciplina fina da observação e indução, o sentido da precisão, do rigor geométrico; mas ninguêm há hoje que se lembre de sustentar que isso baste para a educação do espírito, para a formação do homem. É necessário dar ao espírito humano o conhecimento de si, ensiná-lo a descobrir e entrar na posse de todas as suas energias intelectuais e morais, a aperfeiçoar e depurar os sentimentos, a desenvolver e polir o bom gosto, o senso estético, a amadurecer o juízo, a formar o carácter, a adquirir a linha imperturbável de firmeza e austeridade, ao lado da suave tolerância e polidez, indispensável ao trato social (Vasconcellos [1912] $2002: 30$ ).

8 A justificação que fornece sobre a pertinência das faculdades letras e do seu ensino é de teor político, e não de índole pedagógico-didáctica. Aquelas deveriam proporcionar a educação do espírito, a "formação do homem ", elaborar um programa educativo global. A deslocação desta missão para faculdades entendidas como escolas de formação de agentes de ensino viria a ser contudo a tónica que governos posteriores, ao longo do século, enfatizaram como missão última das faculdades de letras. O autor considera próprio de um regime democrático a divulgação do ensino de letras ; para R. de Vasconcellos, este constitui um enorme contributo para a « educação simultaneamente 
moral, política e cívica » dos cidadãos, à semelhança do que se passa em países mais pequenos do que Portugal, como a Bélgica, a Holanda e a Suíça, que "bem [compreenderam] a necessidade de se facilitar, de se vulgarizar quanto possível a cultura humanista, para criar cidadãos, para dirigir, guiar e civilizar a sociedade ». Considera por isso um erro que os diplomas de letras só sirvam para o magistério, e apela a que a legislação seja " revista e modificada em face das idéas modernas " (Vasconcellos [1912] 2002: 35-36).

9 A indefinição de fronteiras nítidas entre Letras e Ciências é uma constatação sobre a qual assenta o seu discurso. Na impossibilidade de definir campos epistemológicos exclusivos para cada um destes ramos do conhecimento, que nenhuma oposição metodológica parece excluir, fala em espaços de «território misto, onde no seu labutar se encontram as ciências do homem com as ciências da natureza ». Desta imbricação dá vários exemplos :

A psicologia experimental estabelece o contacto íntimo entre as ciências psicológicas e a fisiologia cerebral; a geografia, que não pode separar-se do grupo das sciências históricas, prende naturalmente estas sciências com a fisica do globo; a fonética liga de maneira indestrutível as sciências filológicas e a fisiologia (Vasconcellos [1912] 2002: 29).

10 De facto, para o autor, os campos de Letras e Ciências unem-se pela prática de metodologias comuns, ambos desenvolvendo um ensino prático: « nas Faculdades de Letras, como nas de Sciências, o ensino não pode fazer-se sem exercícios práticos, trabalhos de investigação pessoal», investigação que define igualmente o método das " ciências filológicas ", cujo objecto é "[estudar o homem] nas comunicações dos seus pensamentos e dos seus sentimentos, [sendo] a linguagem [...] tratada como o meio natural de comunicação entre os homens, o processo pelo qual exprimem os seus conceitos, o instrumento constituinte das literaturas» (Vasconcellos [1912] $2002: 29$ ).

No mesmo ano lectivo inaugurado por esta oração de sapiência vem integrar o corpo docente daquela faculdade uma distinta filóloga, admiradora de Portugal, da sua língua, cultura e literatura: Carolina Michaëlis de Vasconcelos.

12 O livro que acima referimos, Lições de Filologia Portuguesa é aberto pelo discurso de apresentação oficial da autora àquela universidade, a 12 de Janeiro de 1912. Trata-se de um curto discurso que nos permite desde já reconstituir quer o perfil da investigadora o seu afastamento de "manifestações públicas ", num tempo que privilegiava o recolhimento do investigador -, quer o lugar que a universidade europeia conferia à mulher. Carolina Michaëlis recorda o impedimento do acesso à universidade durante a sua juventude, não obstante tratar-se da universidade de Berlim, sediada na sua cidade natal, considerada no tempo « a metrópole da inteligência » (Vasconcelos s/d : [5]).

13 Este discurso é ainda revelador do tipo de saber privilegiado à data da fundação das faculdades de letras em Portugal, e da criação das respectivas licenciaturas: letras clássicas, mas também letras modernas, cujos planos de estudo integram as chamadas línguas vivas, ensinadas em disciplinas de "Línguas práticas ». Uma época que privilegiava o saber livresco, pouco interessada na sua divulgação extra muros: « À força tive de ser autodidacta, tendo por mestres apenas livros. $\mathrm{E}$ os livros, eloquentes embora na sua mudez, não nos ensinam a discursar » (Vasconcelos s/d : [5]). Permite-nos ainda tirar ilações sobre o modelo de Universidade que se pretende desenvolver. Uma passagem atesta-o claramente: «Para o bom desempenho das minhas novas funções careço mesmo da indulgência, do conselho e da cooperação efectiva e constante dos 
meus dignos colegas. Com ela conto ; e também com a boa vontade e o zelo instigador dos estudantes - visto que docendo discimus " (Vasconcelos s/d : 6). Tratando-se da Universidade de Coimbra, tanto ou mais significativa se revela esta concepção de uma universidade voltada sobre si mesma, instituindo circuitos de comunicação endógenos, que a oração de sapiência proferida a 19 de Outubro de 1964 por Costa Pimpão recupera ainda, geradores do modelo de reproductibilidade studado por Pierre Bourdieu em várias obras publicadas desde meados do séc. $\mathrm{XX}^{12}$.

O convite endereçado a Carolina Michaëlis situa desde logo a criação dos cursos de Filologia - Clássica, Românica, Germânica - sob a égide do modelo vigente à época, o modelo filológico alemão ${ }^{13}$. A autora defende nestes termos a importância dos estudos proporcionados pelo novo método:

Diante dessas enormidades [a história da vida na Terra] os problemas filológicos parecem minúsculos. Mas não o são. A criação da linguagem é o maior fenómeno e problema social de toda a humanidade. Sem ela não havia história, nem civilização (Vasconcelos s/d: [125]).

E prossegue, « o filólogo deve sempre historiar e, comparando, retroceder até chegar às origens, aos elementos primários " (Vasconcelos s/d: 126), retomando o fio do pensamento desenvolvido na lição inaugural ${ }^{14}$. Especifica o que entende por " elementos primários ": " as partes irredutíveis a que os investigadores chegam, descarnando as palavras de elementos secundários como prefixos, sufixos, infixos, desinências gramaticais, vogais de ligação - são RAíZES - quase sempre monossilábicas tanto nas línguas indo-europeias, históricas, como naquela língua árica, primitiva, hipotética, que quatro gerações de eruditos internacionais, na sua maior parte germânicos, tentaram e tentam abstrair das formas comparadas de todas quantas subsistem - sempre à procura da resolução do enigma que a grande esfinge humana nos propõe quanto às primitivas origens da linguagem: o Milagre do verbo » (Vasconcelos s/ d: 126).

16 Assim se compreende a importância de que se revestia a primazia dada aos estudos medievais, mas também a perspectiva sob a qual estes eram abordados, como a fonte explicativa de toda a modernidade. No conhecimento das " raízes ", por extrapolação da aplicação do método filológico aos estudos literários, se encontraria a « chave » da significação dos textos, e na procura do seu sentido único se exercitavam os leitores/ investigadores/detectives - alunos e mestre -, empenhados na procura da verdade dos textos. Verdade essa coincidente com a "intenção do autor " (intentio auctoris), detectável no estudo da génese do texto, cuja aproximação, através da detecção da sua " voz ", conduziria o leitor à mais fiável fonte de legitimação de qualquer texto. $\mathrm{Na}$ indagação da biografia do autor se encontrariam os elementos " justificativos » da história, sendo a obra considerada como a forma de expressão sublimada de um ser também ele único - génio - , e fonte de autoridade suprema sobre toda a leitura. Do investigador esperava-se então uma postura de fidelidade à intenção do autor, devendo os estudos literários proporcionar o conhecimento do homem e da obra, a famosa díade de natureza causal que Antoine Compagnon não hesitou em aglutinar na expressão original « vieuvre », numa obra cujo título é por demais significativo da viragem que os estudos literários universitários sofrem com Lanson (Compagnon 1983 : 15). Postura biografista que constituía o fim último da investigação filológica aplicada à literatura: a restituição do texto na perenidade do monumento em que se reconstituiu. 
17 Como afirma Bernard Cerquiglini, no ensaio que publica em 1989, Éloge de la variante: Histoire critique de la philologie, livro escrito no rescaldo dos estruturalismos, quando a atenção dos críticos se volta para os manuscritos, na recuperação da sua originalidade de textos fundadores, e por isso tornados objectos de renovado interesse - « la philologie générale »-, a qual « a pour but de retrouver, autant que possible, la forme que l'ouvrage auquel elle s'applique avait en sortant des mains de l'auteur»; " fondée sur une notion transhistorique de l'auteur, origine de son oeuvre dont il maîtrise le sens, elle répond à une exigence transhistorique de reconstruction » (Cerquiglini 1989 : 85). E vale a pena continuar a citar este autor, atento ao fechamento sobre texto e sobre o autor, por um lado, ao qual conduz a perspectiva filológica:

La philologie [...] s'adjoint de façon subreptice une théorie littéraire qui est celle $\mathrm{du}$ génie. Elle fait tenir ensemble une théorie autoritaire du sujet [...], l'idée de l'origine et la notion de stabilité textuelle, en magnifiant un auteur transcendant (Cerquiglini 1989 : 90),

18 e à crença na reconstituição de uma língua original " pura » das quais as línguas faladas na actualidade não são mais do que variantes « impuras ", à qual conduz, por outro lado, a mesma perspectiva. Argumentação fundamental para a ideologia do Estado Novo, quando advoga a criação de um « homem novo », impoluto :

Le moyen le plus efficace de réduire l'hétérogénéité dont s'entache l'ancienne langue est le fantasme d'une perfection révolue.

En cela, le philologue vient au secours du grammairien. La critique des formes donne à l'archétype [...] la pureté simple de la bure originelle (Cerquiglini 1989 : 89).

19 Costa Pimpão alia a definição etimológica de filologia: «amor da ciência; o culto da erudição ou da sabedoria em geral» (Pimpão [1964] 2002 : 129) a um substrato de índole religiosa e patriótica, afirmando na sua lição inaugural do ano de 1964:

O amor e culto das ciências do espírito (Geistes-wissenschaften) - sobretudo da ciência da linguagem, do verbo ou do logos que é distintivo do homem - expressão do pensamento, manifestação da alma nacional, órgão da literatura e instrumento de nós todos, mas principalmente dos letrados que, apesar de tudo quanto contra eles se tenha dito e se possa dizer, são poderosos obreiros de Deus. Sem eles, se ninguém assentasse o que presenciou, pensou e viu, não havia progresso nem civilização (Pimpão [1964] 2002 : 130).

20 Assim se compreende a proximidade entre os estudos de filologia linguística e os de filologia literária, exercendo-se ambos sobre um mesmo objecto - a língua -, e com uma mesma finalidade - o estudo daquilo que é distintivo do homem, a forma de expressão do seu pensamento e a sublimada forma de manifestação da alma nacional. Logo, a mesma postura une filólogos e especialistas de literatura no estudo do dealbar das literaturas nacionais - o que justifica a atribuição de disciplinas de estudo da língua e da literatura aos mesmos docentes, sob uma perspectiva histórica - a da língua e a da literatura ${ }^{15}$. Esta postura privilegia também, por outro lado, o ensino da língua não para fins imediatamente comunicacionais, mas como indagação das referidas «raízes», fim último do conhecimento das várias línguas pertencentes à mesma família. Para esta perspectiva, as formas contemporâneas das várias línguas não são mais do que «variantes» provenientes das ditas «raízes».

21 Carolina Michaëlis, reconhecendo a « imbricação profunda, neste contexto epistemológico, entre estudos literários e estudos filológicos » (Vasconcelos s/d : 152), considera que: 
tanto são filólogos os historiadores e investigadores de literaturas, como os historiadores e investigadores de línguas que procuram resolver cientificamente problemas positivos, historiando e comparando, quer fonéticos, quer morfológicos, sintácticos - gramaticais, portanto - quer etimológicos, semasiológicos, onomasiológicos (lexicográficos) ou dialectológicos - isto é, de origens (Vasconcelos s/d : 154).

Para a autora, o fim último do filólogo seria chegar " porventura a uma única linguagem, desabrochada numa localidade também única, onde nasceu a humanidade, então também unitária » :

Outra monogénese, portanto, num paraíso terreal, mas diversa da bíblica, que fôra divina.

O glotólogo, embora seu assunto seja a língua, deve [...] ser poliglota, conhecer todos os tipos de línguas, investigar a construção e o vocabulário de todos êsses tipos, desde os mais adiantados, com literaturas como a índica, a helénica, a latina, a germânica, até aos falares mais rudes, infantis e pobres, de tribus selvagens que não sabem contar senão até dez, ou apenas até cinco, não distinguem as côres senão rudimentarmente, e só conhecem uma única classe de palavras (Vasconcelos s/d: 154-155).

Depois da lição proferida por R. de Vasconcellos em 1912, as orações de sapiência só voltarão a ser atribuídas a Professores da Faculdade de Letras após a instauração do Estado Novo. As lições proferidas em 1926, por José de O. Guimarães ${ }^{16}$, de formação clássica e teológica; em 1943, por Francisco R. Gonçalves ${ }^{17}$; e, em 1948, pelo geógrafo Amorim Girão, comungam de um ideário comum: a glorificação dos princípios norteadores do Estado Novo.

Em 1926, José de O. Guimarães aborda o problema da « crise da moral filosófica », nos seguintes termos:

Aproveitando-se da renúncia de muitos à penetração do problema moral pelos critérios da sciência, ao tablado da exibição filosófica teem acudido em tropel numerosos sistemas anti-intelectualistas e vai assim assistindo a nossa época ao êxito fácil de teorias intuicionistas, fideistas e pragmáticas, que, desdenhando da razão, do conhecimento indirecto, discursivo, procura entregar à visão misteriosa das energias cripto-psíquicas, aos vislumbres confusos da região sublimiar da consciência a solução dos problemas da acção, como se das trevas pudesse surgir a luz ou da confusão emergir a ordem (Guimarães [1926] 2002 : 61).

Considerando ser « mundana e elegante » a atitude contemporânea de cepticismo em que parece ter caído a sociedade portuguesa perante os valores outrora venerados, o autor apela, num discurso de teor pós-republicano, à necessidade de um ensino moralizante:

Ficou a mocidade das nossas escolas absolutamente desamparada de toda a direç̧ão moral por isso que em nenhum grau de ensino se lhe proporciona de uma maneira verdadeiramente eficaz qualquer ensinamento e qualquer acção, que não só habilite a reflexão a escolher entre os diferentes valores com que as coisas se apresentam [...], como também esclareça a consciência sôbre os critérios que devem presidir á hierarquização dos deveres (Guimarães [1926] 2002 : 68).

A lição que profere nesse dia 16 de Outubro de 1926 poderia constituir um longo parágrafo introdutório a toda uma postura que o Estado Novo viria a desenvolver como objectivo do ensino das línguas - pátria ou estrangeiras - no ensino liceal: mais do que formar para a comunicação, o seu ensino devia constituir uma ocasião relevante para o enraizamento das virtudes de ser português quando confrontado com o outro cuja língua se aprende ${ }^{18}$. E prossegue no mesmo tom, referindo-se ao ensino da literatura ${ }^{19}$ : 
É bem certo que a cultura intelectual feita através do ensino das ciências, sobretudo das de feição literária, pode e deve ser um poderoso auxiliar da formação moral e não é menos certo que a solidariedade que naturalmente suscita a vida escolar também contribue para a desenvolução das tendências sociais, e que ambos êstes factores de cultura e disciplina, quando criteriosamente aproveitados, podem imprimir ao carácter dos educandos uma forma de valor social eficientíssima (Guimarães [1926] 2002 : 68).

27 Em 1943, Francisco R. Gonçalves, na lição intitulada « As Humanidades clássicas e a Universidade de Coimbra » tece a apologia das humanidades clássicas, em nome da perenidade dos valores que transmitem. Entende corresponderem estas e o seu ensino a um período de neutralidade do país, não obstante situar-se em plena $2^{a}$ guerra mundial. Para o autor, elas representam a « Cultura inteira, graças a uma virtude primacial: porque constituem, no dilatado campo do saber humano, o que este possui de menos mutável e transitório » (Gonçalves [1943] 2002 : 82). Trata-se de uma lição da mais pura erudição, em plena guerra, com frequentes transcrições em latim! Num momento em que, concomitantemente ao conflito armado se esboçava o destino pós-colonial europeu, com a formação dos vários movimentos de emancipação que não tardarão em desencadear, a partir de finais dos anos cinquenta, as lutas de independência em várias frentes, pretende-se nesta lição justificar o alinhamento europeu de Portugal com outros países sobre o ensino das línguas clássicas :

Uma prova, entre outras, está em que os países europeus de mais extensos impérios ultramarinos, longe de pretenderem tudo conseguir com os seus recursos linguísticos, reforçam e prolongam com o grego e o latim a vasta obra civilizadora das suas grandes línguas de colonização (Gonçalves [1943] 2002: 86).

Não hesitando em proclamar claramente o seu pensamento colonialista quando não esclavagista $^{20}$ na defesa de um conceito do ensino das " línguas clássicas, tornadas instrumentos civilizadores ", e na constatação de que estas « se constituem, novamente línguas imperiais, pela força imortal do espírito » (Gonçalves [1943] 2002 : 86), o autor é levado a considerar que no limite, a defesa do ensino das línguas clássicas supera o valor da aprendizagem das línguas modernas, subalternizando-as: é enaltecida a sua " função [...] de ginástica mental, que prepara a inteligência para toda a laboração vindoura ", atendendo à sua " estrutura sui generis ", línguas " tão diversas das modernas e por isso mesmo tão apropriadas a fazer-nos pensar de outro modo, fora das simples correspondências mecânicas de língua para língua que roubam ao estudo dos idiomas actuais uma grande parte de valor formal » (Gonçalves [1943] 2002 : 87).

Para Rebelo Gonçalves, o valor das letras clássicas é normativo e instrutivo. Para além disso, o seu ensino justifica-se como cultura subsidiária para outros saberes, abrangendo " variadíssimos sectores da vida mental », desde o direito, filosofia, história e ciências auxiliares (Gonçalves [1943] $2002: 89$ ).

Num discurso de 1943, ainda refere «a moderna orientação filológica, isto é, tudo quanto seja doutrinar sobre a gramática científica, a lexicologia, a etimologia, a história do grego e do latim ». " Não é também a filologia [...] um dos objectos irrecusáveis do ensino superior das letras modernas? » Concebe o ensino filológico "praticado a par com histórico-literário», coincidentes como exegese dos textos, para se alcançar a «alma do povo que o falou » (Gonçalves [1943] 2002: 95).

31 A última destas três lições, proferida a 16 de Outubro de 1948 pelo geógrafo Amorim Girão, « Portugal e a Universidade perante as condições geográficas da Idade Nova » é politicamente coincidente com o « dia em que se inauguram também as primeiras obras 
da Cidade Universitária de Coimbra ». Nela enaltece a consciência de que se inaugura naquele momento uma "idade nova ", cujas responsabilidades " graves " entende deverem ser partilhadas também pela « Mocidade Académica» (Girão [1948] 2002 : $135)^{21}$.

Desenvolve então um discurso centrado sobre o papel civilizador («messiânico ») de Portugal no mundo, ao longo do qual realça o papel da língua portuguesa no confronto com as outras línguas, mas também o papel das línguas entre si. A este propósito cita a importância de que se reveste o Curso de Férias, exemplo não só gratificante e reforçador da aliança com o Brasil, como do papel de Portugal no mundo, modelo de sã convivência entre povos diferentes. Para Girão, a coexistência pacífica entre povos e costumes, unidos na diversidade étnica e linguística, demonstra de que modo a convivialidade lusa constitui um excelente modelo para o projecto de elevado idealismo da ONU. Suspeitoso sobre as « interpretações tendenciosas » que envolvem a expressão " cidadão do mundo » (ideologicamente oposta ao entendimento do conceito de línguanação que subjaz ao seu pensamento sobre o lugar e o valor do ensino das línguas e do posicionamento das línguas entre si), considera que «é uma boa escola de cidadania mundial a dos nossos Cursos de Férias ", comparando-os a " uma pequena Sociedade das Nações Unidas ", enaltecendo o " espírito de concórdia » reinante, e deixa a sua nota política sobre a exclusividade do procedimento que conduzirá ao «ideal supremo de bom entendimento e de boa harmonia entre os homens que a ONU pretende pôr em prática » (Girão [1948] 2002 : 131-132).

As três lições a que acabamos de fazer referência são nitidamente discursos de propaganda, em que o desejo de um ensino das letras como moralizador dos costumes, o valor das línguas clássicas suplantando o teor mecanicista das línguas modernas, reputadas carecerem de substrato cultural, ou a missão da língua portuguesa, colocada como matriz dos falares brasileiro ou africanos, sobrelevam a todo o confronto das línguas entre si, sobrepondo-se a qualquer tipo de reflexão cientificamente fundamentada.

34 Três anos volvidos sobre a II guerra mundial, face a uma Europa arrasada, lemos em Amorim Girão - leitor de Gonzague de Reynolds- o seguinte «diagnóstico»da situação em que o mundo está: não se deverá considerar que se assiste à «agonia de uma civilização [...] mas, bem ao contrário, como simples, e natural, e necessária crise de crescimento», «crise da adolescência» da humanidade (Girão [1948] 2002 : 134).

35 A oração de sapiência proferida a 22 de Outubro de 1960 por Paiva Boléo ${ }^{22}$ denota já uma postura completamente diferente da que surpreendemos nas três lições anteriores, panegíricos políticos fortemente condicionados. Apoiado em argumentos científicos, o autor desenvolve o tema da linguística como ciência da modernidade, na lição em que pretende introduzir uma ciência nova, "Algumas tendências e perspectivas da Linguística moderna ", capaz de modernizar as faculdades de letras. Não descurando a " ciência pura ", mas hostil à permanência do fechamento dos investigadores na sua «torre de marfim», considera que se deverá desenvolver a « linguística aplicada ", que considera tão " legítima e necessária como a linguística teórica e especulativa » (Boléo [1960] 2002 : 166). Esta lição é sintomática da viragem que a disciplina de linguística anuncia perante a investigação, relativamente à postura filológica advogada por Carolina Michaëlis, de um saber ensimesmado: ela é aqui apresentada como introdutora da divulgação do saber para fora dos muros da Universidade. É notória, por outro lado, a preocupação do autor com a aplicabilidade 
dos saberes linguísticos ao enumerar os campos profissionais em que se aqueles revelam a sua especialidade: jurídico, anatómico, mineralógico, industrial, desportivo, económico, administrativo, político, etc. A tradução é um campo que reputa da maior importância. Por isso apela à necessidade de criar " dentro das Universidades " Institutos de Línguas estrangeiras, ou Institutos de Intérpretes ou Tradutores.

A sua defesa do desenvolvimento dos estudos de tradução tem implicações sobre os métodos de ensino de línguas, condenando a aplicação exclusiva do método directo no ensino das línguas vivas. Censura nomeadamente a " convicção [...] de que se deve pensar e falar sempre na língua estrangeira, sem nunca recorrer (ou só a título esporádico) à tradução para a língua materna ». Considera por isso que " praticar, no ensino, quase exclusivamente a oralidade, apresenta graves inconvenientes ». " Praticar o método directo puro, é esquecer o alto valor formativo da tradução, não da versão passiva e mecanizada [...], mas da tradução inteligente e bem preparada, que procura o que é verdadeiramente idiomático, ou seja fazer ver o génio próprio de cada língua ». Por isso se regozija com a prática de certos professores no liceu que praticam a " estilística comparada das duas línguas em presença », aconselhando a leitura de Vinay e Darbelnet, Stylistique comparée du français et de l'anglais (Boléo [1960] 2002 : 170). Para Boléo, a prática da tradução reveste-se de conotações político-sociais: ela desempenha um importante função no estudo das «línguas entre si» às quais estão confrontados os alunos, conferindo-lhes as ferramentas necessárias à sua formação no campo do que chama, inovadoramente, a " cidadania linguística » (Boléo [1960] 2002 : 170). Precursoramente, a lição de Paiva Boléo, assente na crença de que existe na maior parte dos países europeus uma comunidade de civilização, na esteira de Charles Bally (Traité de stylistique française), ao abrigo do que chama a "mentalidade europeia ", revela-se um manifesto em prol da integração de Portugal nesta comunidade, ao abrigo sempre, porém, e no seguimento do pensamento do linguista Bruno Migliorini, que cita, do respeito pelas nacionalidades: «L'Europe doit acquérir de plus en plus la conscience de son unité, et en même temps respecter les nationalités, dans lesquelles réside sa force spirituelle » (Boléo [1960] 2002: 173-175).

Quatro anos volvidos sobre esta lição de «modernidade», a oração de sapiência proferida a 19 de Outubro de 1964 por Costa Pimpão, «As humanidades e o Humanismo de hoje ", insere-se na linha da anteriores lições, que celebravam o valor exclusivo da formação humanística - clássica, latina - para compreender o presente. Partilhando o pensamento colonialista de Amorim Girão, vamos reencontrar neste autor o apelo utópico à continuidade da missão civilizadora do ocidente em África.

Um passo resume o seu conservadorismo, censurando ironicamente a "glorificação " da " ciência moderna ": "Sob esse entusiasmo ingénuo se descobre uma consequência iniludível : a redução progressiva do 'humano', a assimilação do 'homem' a essa matéria que se diz estar sob o seu domínio, mas que na realidade o escraviza » (Pimpão [1964] 2002 : 197). O seu discurso reveste-se assim do tom apocalíptico que já reconhecêramos noutras lições precedentes, e que o leva a caracterizar a actualidade à luz de pensadores do séc. XVIII, como Fontenelle, a quem recorre frequentemente, confessando o clima de medo que sente à sua volta, num mundo em que « não há paz, mas apenas ausência deguerra» (Pimpão [1964] 2002 : 199-200).

No seu discurso não defende a importância do ensino das línguas vivas. Apela antes à " criação de alguns liceus de base humanística, onde as humanidades clássicas voltassem a 
ocupar o lugar que lhes foi usurpado pelas humanidades modernas e pelas ciências positivas $^{23} »$ (Pimpão [1964] 2002 : 202).

Do mesmo modo encara as literaturas modernas como tendo usurpado o lugar das clássicas. Para Pimpão, todo o presente é herança do passado e exige o conhecimento deste : "Que pode conceber-se de mais dignificante para o espírito humano do que seguir, através das grandes linhas do diálogo platónico e após bem mais de dois milénios, a transfiguração do pensamento de Sócrates no poema do grande romântico? " (Pimpão [1964] 2002 : 204). Interroga-se ainda " até que ponto o ensino das humanidades modernas representa de facto um alargamento da cultura ». Considera que pecam pela "indeterminação do objectivo a alcançar " - de natureza cultural, que não têm, " como complemento do ensino das humanidades clássicas ". Só visam "pronunciar bem ", « entender os que falam essa língua », apreender, "pelo contacto pessoal uma cultura diferente ", e nisso reside o " aspecto dramático do ensino das línguas modernas, quer no ensino liceal, quer nas Universidades » (Pimpão [1964] 2002 :205).

Referindo a ausência da formação em humanidades nos Estudos Gerais Ultramarinos, e depois de reconhecer a « unidade de expressão linguística e literária » entre o Brasil e Portugal (Pimpão [1964] 2002 : 210), defende a tese da « África portuguesa » como uma Novíssima Lusitânia que é preciso « formar ». Donde concluir a sua lição com um apelo à introdução das Humanidades em África, como missão da universidade, em particular das faculdades de letras: "Criemos ao espírito as condições de soprar em Africa " (Pimpão [1964] 2002: 211).

42 Concluiremos este estudo na convicção de que não se pode pensar o lugar do ensino das línguas estrangeiras em Portugal separando-o da questão colonial, durante o período do Estado Novo. Atendendo a que este regime se caracterizou pela negação da História, tanto ou mais difícil se torna para o investigador delimitar cronologicamente a expressão " primeiros anos do século XX ", tal como o quer o nosso Colóquio. Estes anos, no caso português, abrangem a implantação da República, a criação das faculdades de letras e largos anos da sua existência: assim se pode explicar a linha de continuidade entre as várias orações de sapiência pronunciadas durante o período em causa, vangloriando a continuidade da missão portuguesa, supra-histórica. À permanência de um regime político corresponde a permanência de determinadas opções epistemológicas e metodológicas. Se bem que não tenham sempre correspondido à prática das aulas de língua - progressivamente atribuídas a leitores, corpo docente dotado de mobilidade e também de grande precariedade - o pensamento que é exposto nas orações de sapiência que analisámos é no entanto fortemente revelador do que poderemos considerar o pensamento oficial de uma Universidade que se pronunciava perante os mais altos dignitários da Nação. 


\section{BIBLIOGRAFIA}

BOLÉO, M. de Paiva. 2002 [1960]. « Algumas tendências e perspectivas da Linguística moderna », in Francisco de Oliveira (coord.). $2002:$ 155-182.

CERQUIGLINI, Bernard.1989. Éloge de la variante: Histoire critique de la philologie. Paris : Seuil.

COMPAGNON, Antoine. 1983. La Troisième République des lettres : de Flaubert à Proust. Paris : Seuil.

GARCIA, M. da G. DIAS; LAUREL, M. H. Amado. 2005. « Ensinar francês tem género? Breve reflexão sobre o discurso jurídico-político e os livros de ensino dos anos sessenta ». Actas APHELLE :

213-256.

GIRÃO, A. de Amorim. [1948]. « Portugal e a Universidade perante as condições geográicas da idade nova », in Francisco de Oliveira (coord.). 2002 : 107-136.

GONÇALVES, F. Rebelo. [1943]. « As Humanidades clássicas e a Universidade de Coimbra », in Francisco de Oliveira (coord.). $2002: 81-101$.

GUIMARÃES, J. J. de Oliveira. [1926]. Oração de sapiência, in Francisco de Oliveira (coord.), 2002 : 51-75.

KOK ESCALLE, M.-Ch. et MELKA, F. (réd.). 2001. Changements politiques et statut des langues : Histoire et épistémologie 1780-1945. Amsterdam-Atlanta, GA : Editions Rodopi B. V.

LAUREL, M. H. Amado. 2000. «Eugénio de Castro, docente da Faculdade de Letras da Universidade de Coimbra: dos caminhos da Velha Alta à consagração coimbrã ». Actas APHELLE : 243-270.

LAUREL, M. H. Amado. 2001. «L'enseignement de la langue et de la littérature françaises au Portugal entre 1910 et 1936 : aspects idéologiques et institutionnels ", in M.-Ch. Kok Escalle et F. Melka (réd.). 2001 : 285-302.

OLIVEIRA, Francisco de (coord). 2002. Orações de sapiência da Faculdade de Letras 1912-1995. Coimbra : Imprensa da Universidade.

PIMPÃO, Á. J. da Costa. 2002 [1964]. « As Humanidades e o Humanismo de hoje », in Francisco de Oliveira (coord.). $2002: 187-211$.

VASCONCELOS, Carolina Michaëlis de. s/d. Lições de Filologia Portuguesa segundo as prelecções feitas aos cursos de 1911/1912 e de 1912/1913, (Seguidas de Lições práticas de Português arcaico). Lisboa : Dinalivro.

VASCONCELLOS, A. G. Ribeiro de. 2002 [1912]. « Lição inaugural do ano lectivo de 1912-1913 », in Francisco de Oliveira (coord.), $2002: 19-46$.

\section{NOTAS}

1. As orações de sapiência são proferidas na sala mais emblemática de toda a universidade - a Sala dos Capelos (séc. XVII) - onde decorrem os principais actos académicos, na presença de altos representantes governamentais, para além das autoridades académicas. À lição inaugural do ano de 1912-1913, assistiu o Ministro da República Portuguesa (Ministro da Marinha); à do ano de 1926, o Presidente do Ministério e o Ministro da Instrução Pública; à do ano de 1943, somente o Reitor da universidade; à do ano de 1948, os Ministros da Educação Nacional e das Obras Públicas; às dos anos de 1952, 1960 e 1964, o Ministro da Educação Nacional. Os textos correspondentes 
para o período entre 1912 e 1995 foram publicados pelo Prof. Francisco de Oliveira, da mesma instituição (v. Oliveira 2002).

2. Carolina Michaëlis de Vasconcelos (Berlim, 1851 - Porto, 1925) foi a mais célebre filóloga da língua portuguesa. Crítica literária, escritora, lexicógrafa, investigadora e a primeira mulher a leccionar numa universidade portuguesa. Teve grande importância como mediadora entre a cultura portuguesa e a cultura alemã. Adquire o apelido Vasconcelos após o enlace com Joaquim António da Fonseca Vasconcelos, musicólogo e historiador de arte. Entre os seus correspondentes, contam-se Eugénio de Castro, Antero de Quental, João de Deus de Nogueira Ramos, Henrique Lopes de Mendonça, José Leite de Vasconcelos, o Conde de Sabugosa, Teófilo Braga, Trindade Coelho, Anselmo Braamcamp Freire, Sousa Viterbo, Alexandre Herculano, os médicos e escritores António Egas Moniz e Ricardo Jorge, os espanhóis Menéndez y Pelayo e Menéndez Pidal, sem falar das personalidades francesas, inglesas e alemãs. Informações colhidas em : http://pt.wikipedia.org/wiki/Carolina_Michaelis, a 12.1.2009.

3. Não referiremos aqui a obra de Teófilo Braga, uma vez que não leccionou na Universidade de Coimbra.

4. Nas referências bibliográficas, indicaremos o ano em que as lições foram proferidas entre [...].

5. Damião Peres (1889 - 1976), professor liceal e mais tarde das Faculdades de Letras das Universidades do Porto (1919-1928) e de Coimbra (1931-1959), historiador. Doutorado honoris causa pelas universidades de Montpillher e Bordéus, membro da Academia das Ciências de Lisboa e fundador da Academia Portuguesa de História. Dirigiu a História de Portugal (1928-1954). Informações colhidas em : http://pt.wikipedia.org/wiki/Dami\%C3\%A3o_Peres, a 12.1.2009. Para além de ter leccionado em várias áreas da História, assumiu diversos cargos: Secretário da Faculdade de Letras, Director do Instituto de Investigação Histórica, da Biblioteca Geral, do Centro de Estudos Geográficos, do Instituto de Estudos Históricos, do Instituto de História Ultramarina.

6. Aristides de Amorim Girão (1895 - 1960), vasta obra no âmbito da geografia. Foi com base nos seus estudos sobre a divisão regional de Portugal que foi traçada a divisão administrativa do continente em províncias, levada a cabo em 1936. Informações colhidas em :

http://pt.wikipedia.org/wiki/Amorim_Gir\%C3\%A3o, a 12.1.2009.

Para além da vasta leccionação na sua área de especialidade, assumiu diversos cargos: Secretário e Bibliotecário da Faculdade de Letras, Director do Instituto de Estudos Geográficos, da Faculdade, Fundador e Director do Boletim do Centro de Estudos Geográficos.

7. António Garcia Ribeiro de Vasconcellos (Fac. de Teologia), transitou para a recém-criada Fac. de Letras em 1911. Para além de disciplinas da área de História, leccionou ainda disciplinas de Filologia Românica e Filologia Portuguesa. Director da Faculdade de Letras, do Arquivo e da Capela da Universidade, bem como da Secção de História do Instituto de Estudos Históricos.

8. Após o fechamento da Fac. das Artes decretado pelo Marquês de Pombal.

9. A 5 de Outubro de 1910 é instituído o regime republicano em Portugal, após oito séculos de regime monárquico.

10. Sobre a importância institucional, à data, da Universidade de Coimbra, cf. Laurel, M. H. Amado. 2000: 249, nota 13. Sobre os contornos ideológicos e institucionais da criação das faculdades de letras, cf. Laurel, M. H. Amado. 2001: 287-288.

11. É interessante verificar que inclui a Turquia no grupo de países europeus para cujo périplo universitário convida o seu leitor. Considera que a faculdade " humanística " é a "mais importante das Faculdades » da Universidade de Constantinopla, tendo por missão « ministrar o ensino histórico-geográfico e filológico » (Vasconcellos [1912] $2002: 34-35$ ).

12. Cf., entre outras, Pierre Bourdieu 1973. La reproduction: éléments pour une théorie du système d'enseignement. Paris : Minuit, id., 1975. Les héritiers : les étudiants et la culture. Paris : Minuit ; ou a obra mais recente, id., Langage et pouvoir symbolique. 2001. Paris: Seuil, Points Essais. 
13. A leitura da obra citada de Carolina Michaëlis constitui um documento importante para o conhecimento da história da filologia, cuja fundação situa no início do século XIX, no seguimento da descoberta 'espiritual' da Índia pelos irmãos Schlegel, e depois de Franz Bopp ter demonstrado o parentesco do sânscrito com os principais idiomas cultos da Europa, na origem da filologia Indo-germânica" (Vasconcelos s/d : 133). Salientando o contributo de Jakob Grimm para o estudo dos fundamentos da Filologia germânica e de Friedrich Diez para a filologia românica (neolatina), atribui ao especialista da literatura provençal F. Mahn, o primeiro emprego da expressão «Filologia Românica », em 1833 (Vasconcelos s/d: 133, nota 20).

14. Não existe registo impresso deste curso, segundo nota do editor à edição consultada (Vasconcelos s/d. : 126).

15. Assim aconteceu com Paiva Boléo, como veremos, com Eugénio de Castro, poeta e também director da mesma faculdade, que leccionou em estudos espanhóis, italianos e franceses, ou com o lusófilo Raymond Bernard, tradutor de Eugénio de Castro, docente de língua e literatura francesa alemã, espanhola e italiana entre os anos 20 e 30.

16. José de O. Guimarães transitou da Faculdade de Teologia para a recém-criada Faculdade de Letras. Para além de ter leccionado disciplinas de línguas clássicas, leccionou Filologia portuguesa, Gramática comparada das Línguas Românicas. Desempenhou entre outros cargos os de Reitor interino da Universidade e de Director da Faculdade de Letras.

17. Francisco R. Gonçalves (1907-1982), de formação filológica (estudos clássicos), desenvolveu investigação em lexicografia da língua portuguesa, ensinou nas universidades de Coimbra, Lisboa e São Paulo (1935-1938). Participou na Conferência Ortográfica Luso-Brasileira, na origem ao Acordo Ortográfico da Língua Portuguesa de 1945. Cf. :

https://pt.wikipedia.org/wiki/Faculdade_de_Letras_da_Universidade_de_Coimbra, a 12.1.2009.

18. Tive ocasião de analisar os objectivos do ensino da língua francesa no ensino liceal durante o período em causa in Garcia \& Laurel 2005 : 230-256.

19. O ensino das línguas era apoiado sobre textos literários.

20. Assim é que o autor considera o uso " não só erudito, mas até artístico, e requintadamente artístico, [do grego ou do latim] por homens de cor », ou refere o episódio dos « escravozitos de Clenardo, a quem o humanista só falava na língua de Roma, para que um dia lhe servissem de secretários ", enaltecendo as virtudes da "transmissão do latim a jovens negros » (Gonçalves [1943] 2002: 86)

21. Reflicta-se sobre a importância simbólica da data desta lição, e do seu teor, veementemente patriótico, coincidindo com o início daqueles trabalhos. As reacções ao projecto de destruição da velha Alta pelo ditador, no sentido de dispersar as suas antigas faculdades e colégios residenciais para melhor controlar a Universidade, atestam a dificuldade do domínio da vetusta instituição por Salazar, que não conseguiu contudo lograr a separação entre os edifícios da Faculdade de Direito e de Medicina, nem a sua deslocalização - ambos tendo permanecido sediados no alto da colina de Minerva - bastiões simbólicos do poder no país, de onde emanou grande parte da classe política de então.

22. Leccionou : Literatura portuguesa, italiana e francesa, Filologia portuguesa, Gramática comparada das Línguas românicas, para além das disciplinas da especialidade linguística. Foi director dos Institutos de Estudos Espanhóis, Românicos e Italianos, secretário da redacção do Boletim de Filologia, da revista Biblos, e do Curso para Estrangeiros. Fundou a Revista Portuguesa de Filologia.

23. Itálico nosso. 


\section{RESUMOS}

Propor-me-ia abordar, na minha comunicação, a emergência do ensino das línguas estrangeiras nas faculdades de letras em Portugal, a partir da sua fundação, em 1911, e ao longo do período do «Estado Novo». Tentarei analisar esta situação referindo-me às motivações de ordem institucional, política, cultural que justificaram a criação das faculdades de letras e aos seus objectivos de formação, bem como à fundamentação científica da matriz filológica no ensino das línguas estrangeiras.

In this communication, my aim is to approach the emergence of foreign language teaching at Art faculties in Portugal, from its establishment in 1911 and throughout the "Estado Novo" period. I shall attempt to analyse this situation by referring to the motivations of a cultural, political and institutional nature, which justified the creation of Art faculties and its training objectives, as well as the scientific basis of the philological source in foreign language teaching.

\section{ÍNDICE}

Mots-clés: enseignement de la littérature, humanités, philologie, politique d'enseignement, refrains, XXe siècle

Keywords: Arts faculties, Humanities, Philology, proverbs, teaching politics, XXth century

\section{AUTOR}

MARIA HERMÍNIA AMADO LAUREL

Universidade de Aveiro 